DOI: https://doi.org/10.47405/mjssh.v5i9.494

\begin{tabular}{|c|c|}
\hline & Malaysian Journal of Social Sciences and Humanities (MJSSH) \\
\hline Malaysian Journal of & Volume 5, Issue 9, September 2020 \\
\hline $\begin{array}{l}\text { Humantites } \\
\text { (MJ - SSH) }\end{array}$ & e-ISSN : 2504-8562 \\
\hline & $\begin{array}{l}\text { Journal home page: } \\
\text { www.msocialsciences.com }\end{array}$ \\
\hline
\end{tabular}

\title{
Challenges of Learning English in 21st Century: Online vs. Traditional During Covid-19
}

\author{
Isai Amuthan Krishnan', Hee Sio Ching², Selva Jothni Ramalingam', Elanttamil Maruthai', \\ Pushpa Kandasamy3, Geraldine De Mello4, Saravanan Munian5, Wong Woei Ling6 \\ 1 Faculty of Languages and Linguistics, University of Malaya (UM) \\ 2ELM Business School, HELP University \\ 3SMK Dato' Bentara Dalam, Segamat, Johor \\ 4Jabatan Bahasa Inggeris, Akademi Pengajian Bahasa, UiTM Cawangan Melaka \\ 5SRJKT Ganesar Serdang, Kedah \\ ${ }^{6}$ Kuching District Education Office, Kuching, Sarawak
}

Correspondence: Isai Amuthan Krishnan (amuthan.isai@gmail.com)

\begin{abstract}
Free online resources are user-friendly technologies which have become available through the Internet in recent years and gaining popularity during Covid-19. Since learners use smartphones, free online resources are easily accessible. Books are portable, but learners find it somewhat difficult to learn English language via books which may only be available in the classroom context, whereas free online resources are easily accessed. The purpose of this study is to identify learners' perception learning English via free online resources and traditional learning. Quantitative and qualitative methods were employed in the present study. Twenty-five international pre-elementary intensive English students took part in this study. It was found that learners perceived the free online resources as valuable tools for learning English in relation to reading, conversation, and vocabulary and also free online resources help promote free learning norms in learning the English language. The learners also had constructive attitudes towards free online resources. Free online resources always provide a motivating learning environment, enhance learners' analytical and critical thinking skills, and encourage social interaction between teachers and learners, learners and their peers, and learners and other participants.
\end{abstract}

Keywords: free online resources, traditional, attitudes' accessible, coronavirus, Covid-19

\section{Introduction}

Coronavirus disease 2019 (COVID-19) originating from Hubei Province of the People's Republic of China has become a current pandemic over the world. Many countries have been affected by this virus. In late January 2020, a global health emergency state was announced by the WHO Emergency Committee as COVID-19 confirmed cases have been increasing internationally (McAleer, 2020; Velavan \& Meyer, 2020). COVID-19 has spread in all continents, but Antarctica as of 26 February 2020. Latest news on COVID-19 have overloaded worldwide mass media every day in 2020 (McAleer, 2020).

Our lives have been aligned and shaped by many technologies, and we need to adapt to using current electronic devices. People around the world are now obtaining education online based on such resources' efficacy, making use of online content and taking online courses to prepare for good careers 
(Rahman, Singh \& Pandian, 2018). Nonetheless, issues have arisen in terms of quality in content delivery, assessments, technological limitations, and much more. Such problems demotivate the students in learning or enhancing their educations (Riel \& Polin, 2004) and Schwen and Hara (2004). Online education providers and teachers have often failed to meet the students' requirements. It should be recalled that technology has been updated (Shamim, 2017; Atmojo \& Nugroho, 2020).

In today's world, everything is done for speed, including learning. Learning of language occurs in many forms and fashions and self-study is one of the most common and significant means of learning of a language (Small, 2014. From a personal perspective, a learner can progress and enhance her language knowledge and skills from as little as an hour's self-study a week. Having said that, we also cannot disregard the fact that still, a large number of learners opt to study language via online resources (Marta, 2018; Krishnan, Mello, Kok, Sabapathy, Munian, Ching, Kandasamy, Ramalingam, Baskaran \& Kanan (2020). This is mainly owing to their time constraints. Even as these students commence their first lessons, they pretty well establish the fact that they do not have time for doing homework (Leow, Cerezo \& Baralt, 2015). This raises the question of how to enable students with tight schedules to find time for learning a language Paulsen (2001). This question is met with a simple answer free online learning. Usage of free online learning via free online resources is on the rise.

The increasing number of portable, digital, Android, smart and intelligent devices has been the main contributor to this (Kress, 2013). This gives a good solution to the issue at hand. Now it is possible to offer students the flexibility to acquire knowledge at their own convenience, in any place and at any time (Shahida Naz, Memona Rasheed \& Tahir Rasheed, 2019).

Various works of literature, articles, and scholarly publications have been done on ways to make use of the free Internet resources to aid in the learning of a language (Felix, 2001; Osuna \& Meskill, 1998; Singhal, 1997; Sperling, 1997; Warschauer, 1995; Warschauer, Schetzer, \& Meloni, 2000). Likewise, an abundance of websites present accumulations of online materials for language teachers (Depoe, 2001; Kitao \& Kitao, 2000). Many useful suggestions and ideas on how to use online resources as tools for teaching are also provided by websites. It is very common and easy to find a website today that provides adequate teaching aids for ESL learning. These resources are mostly provided freely (Sussex \& White, 1996; Warschauer, 2000). According to Li and Hart (1996; Wicks, 2010), the web acts as an attractive tool for teaching. This is greatly due to its interactive functions and multimedia capabilities. Thus, online learning increases the motivation for continued learning in students (Meloni, 1998).

Free Online Learning can be defined as instructional environments provided and supported by the Internet. When we say online learning, it encompasses a spectrum of programs based on the Internet that can be accessed in or out of school walls (Lin, Zhang \& Zheng, 2017). Their main purpose is to give a resource of teaching and learning materials with instructions and guides. They also act as facilitation for teachers and learners (Krafcik 2010; Olster 2010). There are several types of online learning. Some are based purely online, and some incorporate face-to-face interactions (Picciano \& Seaman, 2009; Lin, Zhang \& Zheng, 2017).

Blended learning (Watson \& Gemin 2008) acts to sandwich online learning and traditional learning. This approach is known for quality improvement for traditional learning as it merges and enhances established traditional instruction with online learning. Through this, learners are exposed to the online world during the Covid-19. Their work is no longer restricted to the teacher but is extended to other students and people beyond the classroom, which includes a global community (Watson, 2010).

Although the term blended and online are theoretically and commonly implied, blended learning or instruction consists of many forms and is still evolving in alignment with technology (Barab, Squire \& Dueber, 2000). Despite online and blended instruction bringing transformation to instructional processes, there is always room for improvement and reduction of costs. With the increase of demand for online-based learning, especially from secondary school students, it is important to factor in the details of its implementation so as to ensure that it is more productive than other methods of instruction. 
The aim of this paper is to provide insights to policymakers as well as educational administrators to be well informed of the facts about online learning and its potential impacts on productivity in the process of education. This study offers fundamental knowledge to evaluate and comprehend the potential contributions derived from online learning, followed by review of the research on how this online learning provides more benefits in comparison with traditional brick-and-mortar schools.

\section{Literature Review}

Weblogs, also referred to as blogs, which in this context, may be characterised as computer-mediated communication $(\mathrm{CMC})$, provide another resource for online communication (Murray \& Hourigan, 2008). These resources are getting much attention lately in the educational arena, especially in language learning contexts. A weblog is a free, user-friendly technology. It is easily created, customized, sustained, and regularly updated. The entries in these websites are usually arranged in reverse chronological order and are often updated with new facts on particular matters. This information can be written by the owner of the site and can be cited from other websites. Kress (2003) states that the multimodality feature made weblogs look more attractive to access and keen to know the content of weblogs. This multimodality feature consists of colours, audio, video files, images, texts (profile, reflections, and feedback) and hyperlinks to other websites related to the author's interests (Du \& Wagner, 2007; Smith \& Baber, 2005). According to Zhang (2009), weblog posts are usually arranged in reverse chronological sequence, meaning the latest published entry in the blog will be placed at the top of the blog, which includes its date. This makes it easier for the reader to identify the latest or the most recent posts (Zhang, 2009). Furthermore, the blogs can be edited by the blogger (author) and they can be searchable or archived through a database for future reference (Pinkman, 2005).

There are three types of Weblog which are commonly utilised for the language classroom. These are learner blogs, class blogs, and tutor blogs. A learner blog offers learners the functionality to post their understandings and thoughts in relation to their reading. Through this, learners are able to self-express as well as to develop a sense of ownership. In a class blog, learners can post images, messages, and links pertaining to classroom discussions. This can facilitate project-based language learning, and it also can act as a platform for international classroom language exchange (Campbell, 2003). Tutor blogs are deployed with student reading practices, online exchanges, and linked resources for selfstudy.

These free online blogs have been found to produce significantly improved results for English language education for several reasons. Opportunity for real communications can be seen in these reliable learning environments. In these weblogs, the audience is able to interact freely, not only the teacher but inclusive of other people such as classmates and the global online community. Consequently, weblogs promote an awareness of readership and authorship. With this platform, the writers put out opinions, happenings, ideas, and information, while allowing other readers to provide feedback to the blog writers' posts (Benson \& Reyman, 2009; Du \& Wagner, 2007; Kavaliauskieno, Anusieno, \& Mazeikieno, 2006; Oravec, 2002; Ward, 2004). The researchers also stressed that blogs help the reader to enhance reading and comprehension, improve writing abilities and skills, promote a learning atmosphere for reading and writing (Pinkman, 2005), and encourage the learner to be independent (Ward, 2004). According to Du and Wagner (2007), free online resources also have much more to offer, such as online alternative logs whereby the students can document their learning experience. Mynard's (2007) findings also support the advantages that these resources can be instrumental for linguistic teachers in inspiring learners to add input or comments to other people's blogs, which will promote reflections and also enhance their learning experience. In addition, online learning also boosts students in adopting skills such as critical and analytical thinking. Hence, whenever a blogger composes their blog, they are very cautious as to what they write or post as they know that their work will be circulated and viewed in online mode. In response, according to Oravec (2002) and Zhang (2009), the readers, upon reading, would leave ideas and feedback comments for the blog owner. Yang (2005) believes that bloggers are motivated and their critical thinking skills are reinforced by exchanging ideas through an electronic medium. blogging also empowers the formation 
of learning communities and social networks, where the bloggers share their thoughts or convey their ideas more conveniently. This process allows knowledge to be structured and constructed. Hence, blogging enables collaborative approaches to take place in the area of writing and reading on websites (Alexander, 2006; Godwin-Jones, 2003; Kavaliauskieno, Anusieno, \& Mazeikieno, 2006; Sevelj, 2006).

The real communication with free online resources includes reading and writing taking place in an authentic environment with a real audience. It has, therefore, been proven that online learning creates a genuine platform and learning space for EFL learners. This is important because some learners may have limited opportunities to develop their language proficiency in an authentic environment. Some studies have confirmed that students are motivated to read and write using free online, which increases the interest of the students in EFL learning. It also helps learners to be independent and autonomous (Pinkman, 2005; Zhang, 2009).

Therefore, the present study is to attempt to fill the gap of the impact of online learning on student's experiences, perceptions, and their learning attitudes concerning free online resources. This study also investigated the distinguishing features between free online learning versus conventional learning in classrooms and compares the major scope of learning effectiveness.

\section{Methodology}

\section{Consent}

A consent was obtained from the college as well as the students. Both have agreed to conduct the present study. The college was not allowed to attach any transcription as an appendix in this article.

\section{Setting}

This study was conducted in one of the private colleges. This college is located in the city center of Kuala Lumpur. The college has been established since 1984. This college offers ACCA programme, diploma and short courses. Intensive English is one of the short courses.

\section{Sampling}

Fifty-five intensive English, pre-elementary-level students participated in this study. They were international students from 16 countries who came to Malaysia to pursue their tertiary education. They are between 18 to 24 years old. The data started collecting during the Covid-19 (December 2019February 2020.

They were requested to sit for an English placement test before pursuing their studies in foundation and diploma courses in any disciplines. The English placement test was to determine their English language proficiency as this is one of the entry requirements of the college. Those students had not met the requirements to attend a short course, which is an intensive English program. This program consists of four levels: pre-elementary, elementary, intermediate and advanced.

After completing the intensive English program, they were required to sit for an international exam, which was the Cambridge ESOL Examination (English Speakers Other Languages) as this is also one of the entry requirements of the college. The ESOL exam enables students to demonstrate their command of English. Successful results would indicate that the students could succeed in their tertiary education without facing any barriers in doing assignments and sitting for examinations as English is the intended medium of instruction.

The students were strongly requested to incorporate online learning parallel to their classroom learning throughout their English program. This method is also known as blended learning. They were strongly 
encouraged to learn English language using the free online resources. Students was advised to treat technology as an intellectual partner and utilize the technology appropriately in learning.

\section{Instrument}

In the present study, there were two instruments were utilised. The first was a set of questionnaires to investigate the learners' perception and attitudes towards the use of free online resources as compared to books. The questionnaires were adapted by the studies of Mazeikieno (2006), Mynard (2007) Zhang (2009) Anusieno and Mazeikieno (2006) and Marta (2018). The questionnaire consists of two sections; section A on demographic, section B on learners' perception and attitudes towards the use of free online resources and books. The questionnaire has been constructed with 4-point Liker Scales; strongly agree, agrees, disagree and strongly disagree in a very simple English as their English language proficiency at basic users as per Common European Framework References for Language (CEFR). Four Likert Scales were chosen to lessen the neutral responses from the participants. This was supported by Drever (1990) that the questionnaire should be helpful and easy to answer with desires.

The second was in-depth interview was used as a tool to elicit data. As justified by Creswell (2014) and Jackson (2012), the in-depth interview is a qualitative method of analysis to ask questions where participants would be able to promptly answer questions openly and responsively and through answers, probe more questions (Bernard, 2000; LeCompte \& Schensul, 1999; Pathak \& Charatdao, 2012). The participants responded well to in-depth interview conducted by the researcher; however, recording of the interviews was not performed as the participants were not in favour of voice recording. The researcher had to spend almost 5-6 minutes for each participant, which totalled approximately two hours and 30 minutes, jotting down their responses.

\section{Reliability and Validity}

Reliability testing was conducted on the questionnaire. SPSS version 26 was used the analyse the data. The result shows 0.8 which is valid according to Howitt and Cramer (2005) who stated that of the reliability result is above 0.7 the questionnaire is valid to use. Although the questionnaires were adapted from Mazeikieno (2006), Mynard (2007) Zhang (2009) Anusieno and Mazeikieno (2006) and Marta (2018), pilot test was done and the result shows 0.855 which is also accepted as noted by Howitt and Cramer (2005).

Table 1: Cronbach's Alpha

\begin{tabular}{lll}
\hline Cronbach's Alpha & $\begin{array}{l}\text { Cronbach's Alpha Based on } \\
\text { Standardized Items }\end{array}$ & No of Items \\
\hline .855 & .854 & 16 \\
\hline
\end{tabular}

\section{Analysis and Discussion}

\section{Descriptive analysis on Demographic}

All 25 participants were intensive English students. 23\% males and 77 females. Most of the participants between $19-25$ years old. $80 \%$ of the participants used smart handphones and $20 \%$ used laptops to access to free online learning. The participants were asked about the frequencies they use a set of online resources. The most predominantly used resources were social media $(\mathrm{M}=3.55)$, Google $(\mathrm{M}=5.33)$, YouTube $(\mathrm{M}=6.75), \mathrm{B} \operatorname{logs}(3.53)$ and book $(\mathrm{M}=2.33)$. See Table the mean of participants' response. 
DOI: https://doi.org/10.47405/mjssh.v5i9.494

Table 2: Mean of the Participants' Response

\begin{tabular}{llll}
\hline & $\begin{array}{l}\text { Number of } \\
\text { Participants }\end{array}$ & $\begin{array}{l}\text { Mean } \\
\text { (M) }\end{array}$ & $\begin{array}{l}\text { Standard } \\
\text { Deviation } \\
\text { (SD) }\end{array}$ \\
\hline Participants' perception & 55 & 3.99 & 0.874 \\
\hline
\end{tabular}

Table 2 shows the learners' perception learning English via free online resources and traditional learning. It was found that 3.99 very high and the standard deviation shows 0.873 which the participants responded positively that they were more online learning than traditional learning.

Table 3 shows most of the students predominantly preferred online learning was more helpful to the students with their English Language mastery compared to the results gained through traditional learning. From the Table 3, it was evident that the adoption and integration of online resources with traditional methods will lead our education system to the path of success.

Table 3: Perception of Learning English Via Online and Traditional Learning

\begin{tabular}{|c|c|c|}
\hline Items & Questions & $\begin{array}{l}\text { Strongly } \\
\text { Agree/ } \\
\text { Agree }\end{array}$ \\
\hline 1 & Do you prefer to study English Via Online or Book & $99 \%$ \\
\hline 2 & $\begin{array}{l}\text { Do you think you can learn English easily via online free } \\
\text { resources }\end{array}$ & $96 \%$ \\
\hline 3 & Do you think you can learn English easily via books & $12 \%$ \\
\hline 4 & Do you like to carry books to the class? & $11 \%$ \\
\hline 5 & Do you like to carry smart phones and laptop? & $97 \%$ \\
\hline 6 & Do you prefer paper exercises? & $42 \%$ \\
\hline \multirow[t]{2}{*}{7} & Do you prefer online exercise & $92 \%$ \\
\hline & $\begin{array}{l}\text { Do you think you can improve your speaking, listening, } \\
\text { writing and reading via accessing YouTube? }\end{array}$ & $93 \%$ \\
\hline 8 & $\begin{array}{l}\text { Do you think you can improve your speaking, listening, } \\
\text { writing and reading via books? }\end{array}$ & $43 \%$ \\
\hline 9 & $\begin{array}{l}\text { Do you think you can learn vocabulary via online } \\
\text { resources? }\end{array}$ & $92 ?$ \\
\hline 10 & Do you think you can learn vocabulary reading books? & $30 \%$ \\
\hline 11 & Do you benefit by doing online exercising? & $89 ?$ \\
\hline 12 & Do you feel comfortable in doing online exercising? & $98 \%$ \\
\hline 14 & Do you benefit by doing exercise through books? & $12 \%$ \\
\hline 15 & Do you feel comfortable by doing exercise through books? & $10 \%$ \\
\hline 16 & Do you need a teacher to learn English & $90 \%$ \\
\hline
\end{tabular}

The results showed that the participants were engrossed and motivated to use free online resources as an additional tool for learning English during the Covid-19. This method has offered a variety of learning prospects.

Based on the in-depth interview with the 55 participants, it was found that online learning acts as student-oriented learning, where the tools caused the learners to be more versatile. According to the participants, learning was more meaningful and in-depth as there were opportunities for selfexpression. Based on their responses, this particular tool has engaged learning activities in the four major components of English language skills: speaking, reading, writing, and listening. It also allowed learners to further enhance their skills in areas such as grammar, pronunciation, spelling, and vocabulary development at their own pace. 
By utilizing free online resources, learners were able to perceive the message without having hardcopy materials, such as a dictionaries or other learning materials such as textbooks, workbooks, or reference books. For example, referring to a dictionary requires skill, a skill to flip pages according to the alphabetical system and find the vocabulary that you are seeking. If one does not have that skill, searching for a meaning of a particular word would take time and eventually a learner would give up on their search. This contrasts with online dictionaries that are always freely available, which a learner is only required to key-in a particular word in a search dialogue and just click 'enter' to search. Within a few seconds, a whole page appears providing meanings, synonyms, antonyms, and other useful information. Learners felt that this is time saving compared to traditional dictionaries that require page flipping and searching for the words according to the alphabetical system. The functions of the traditional dictionary and online dictionary are otherwise quite similar. They provide meanings, grammatical classifications of words, example sentences, and phonetic symbols that assist learners to pronounce words correctly.

The additional advantage of online dictionaries is that learners have the opportunity to listen to how the words are pronounced either in British English or American English and they allow learners to practice saying them. This inspires and enhances learners to acquire the language freely and selfreliant.

The availability of these online sites allows learners to learn English independently. This instils confidence in learners for learning the particular language. Apart from assisting their reading skills, edictionaries help learners to gain knowledge in vocabulary development and grammatical classification of words. E-dictionaries also function as thesauri, providing a vocabulary list with words of similar and opposite meaning. This tool is very useful for acquiring writing skills. Learners are inspired to plan, draft, and refer to references, check spelling errors, and so on.

There are also several other factors that contribute to greater impact on learners in learning the English language via free online resources. There are numerous websites specially designed to teach ESL (English as a second language) (Atmojo \& Nugroho, 2020). These websites become platforms for learners (students) to utilize as textbooks or workbooks. Meanwhile, teachers also upload relevant materials for learning. The ESL websites provide updated materials. For instance, the reading comprehension materials are designed or upgraded to meet current learning requirements. The sites are also equipped with questions that allow learners to actively participate. The activities posted there are also in various forms. This provides students with multiple options to practice their comprehension or improve their competence level. As for promoting vocabulary development, these sites offer many activities such as matching, word puzzles, cloze passages, or filling in missing letters. These kinds of activity facilitate the learner in the acquisition of knowledge in a fun environment. At the same time, they can also check their answers and make immediate corrections, thus allowing them to learn from their mistakes.

Another factor that gives a good impression to learners about online free resources is the listening activities. The listening activities available online allow learners to engage with their receptive skills to skim and scan information while listening. The various listening activities offered range from easy to difficult depending on the learner's level. Learners can, for example, choose to start from the basic level or beginner level. The exercises involved are those such as listening activities, such as giving directions, eating out, traveling, describing work, and shopping. The exercises include matching and checking understanding with multiple choice answers. This enables the learners to get engaged with the activities and check for the correct answers. Meanwhile, learners also have the option to download the listening file for speaking practice, such as mimicking the conversation. This encourages learners to speak with confidence by utilizing key phrases used in the activities. The listening activities are intense and rich, allowing learners to practice speaking with transcripts available for downloading and viewing. Similar to e-dictionaries, online listening activities are more user friendly to learners compared to listening activities provided on CD or DVD ROMs along with textbooks. In order to play a CD or DVD-ROM, learners need to have computers or laptops that have built-in or external optical drives. Tablets, such as iPads, however, do not have optical drives, and are therefore unable to play the listening activities. In addition, transcripts for listening activities can only be found in the 
accompanying textbooks, the text printed in the transcripts are also in small sized fonts and at times difficult to read. Online free listening activities, or e-listening, provides learners with some configuration options for tasks. Learners can, for example, adjust or increase the size of fonts displayed on websites for their comfort. The listening activities are easily accessed with most devices as long there is internet connectivity. Otherwise, learners can download listening activities and perform the activities at a later time.

Other examples of online activities that are available for free include participating in forums and discussions as well as creating and writing blogs. According to Godwin-Jones (2003), Alexander (2006), Kavaliauskieno, Anusieno, and Mazeikieno (2006), and Sewelj (2006), the process of blogging is an interactive activity that inspires the author to interact directly and exchange information with readers. Furthermore, blogging promotes learners' autonomy. This is because it encourages learners to create weblogs according to the learners' creativity, expression, and ideas. Learners are given the autonomy to make decisions on how and when to create a blog, followed by expression and ideas, which promotes creative thinking. In their blogs, learners have the opportunity to be expressive in their writing, being creative in using styles of text for publishing as well as uploading pictures and videos to make the blogs attractive for readers to view.

Furthermore, blogging gives the young generation experience with the internet community that connects readers globally. Through blogging, learners practice their writing skills, developing vocabulary, constructing sentences, and learning to write cohesively. Learners are inspired to compose writing that involves planning, context, and organization, which is more exciting than paper-based writing. This is because their writing styles will be published in the weblog, reaching readers. Lecturers and teachers from colleges and universities also play an important role in promoting learners' blogging. They (lecturers and teachers) encourage learners to create and write blogs as a part of the learning program as both active and passive learners can participate. Blogging also helps passive learners to self-express in weblogs, reinforces language learning, and, at the same time, enhances their writing skills. This is aligned with the outcomes from research conducted by Ward (2004), Pinkman (2005), and Zhang (2009), which found that learners gave positive feedback in writing weblogs as it assisted them in enhancing their writing skills and in interacting socially. Therefore, blogging promotes learners in social interaction, engages learners in a learning community and enhances learners' analytical and critical thinking skills. This platform encourages learners to exchange ideas and opinions globally.

Forum and group discussion is another online activity in which learners could participate freely. A forum is a platform where people from similar backgrounds share their comments on certain topics. It provides opportunities for exchanging ideas, views, and interests. Learners are given the ability to comment and share opinions, thus empowering them to be methodical and critical. This is in aligned with the findings of Oravec (2002), that online meetings and discussions allow learners to be more analytical when exchanging information.

In brief, the factors presented earlier demonstrated the impact of free online resources on current trends in learning styles. The Internet provides various resources and promotes self-expression and independent learning. It fosters learners to be more critical and analytical when giving views and expression. Learners are motivated in this environment as it gives a sense of ownership and readership. Therefore, it enhances learners in social interaction between readers, forum users, friends, teachers, and the global audience and increases the autonomy of learning, which is crucial for young learners. Through this advancement, learning a second language becomes easy and fun.

Since the inception of the internet and free online resources, many lectures actively converted to online lectures, or e-lectures, for learners. The traditional classroom learning still continues, but electures enable learners to continue learning at any convenient time. For example, if a learner had to be absent for a particular lesson, he or she can still be updated on the lessons and partake in the assignments and online discussions. This motivates learners to be consistent in learning the target language (Twigg, 2003a, 2003b). Classroom teachers and lecturers could make the e-lectures or elearning more interactive by adding games, and other fun tasks. These games may take the form of 
situational activities. Games will expose learners to new vocabulary, phrases, and making decisions, which are higher-order thinking skills.

Another strong reason for encouraging learners to use free online resources for learning is accessibility. It is easy to get access online since most cafes, restaurants, and buildings have wireless Internet connectivity. This makes online learning convenient. Learners can refer to online resources at their own pace. They can complete tasks, refer to dictionaries, and write essays or blogs while having a drink or meal. Easy access to free online resources offer learners the opportunity to practice reading and writing, and to communicate with others. Both passive and active learners are encouraged to interact, share experiences, information, and ideas. Moreover, communicating with peers makes learning more meaningful as learners begin to develop strategies for learning from their classmates' styles of writing or other modes of communication. With the addition of smartphones, online resource learning is made available. In other words, smartphones usually come with Internet data plans purchased as packages from cellular service providers, making the Internet accessible most anyplace, any time of the day. Learners are able to access while waiting for transportation, in transportation, or in restaurants and cafes. This makes learning easily accessible anywhere and anytime.

Overall findings showed that students display positive attitudes toward free online resources. Without exception, all students agreed that they liked the free online materials because they realised that those materials and the associated exercises found on the websites contributed to their English language proficiency. They managed to develop their reading and writing skills by learning proper grammar and building up vocabulary. Furthermore, they also gained exposure to blogging. They realised that developing, publishing, and editing blogs was easy. Learners were attracted by the documenting experiences and the commenting facilities. Otherwise, some students liked the variety of templates and opportunities to design the appearance of their blogs. Eight students were affirmative about interacting with a real audience, sharing ideas and views exchanges; therefore, the activity created opportunities to make friends. They felt that free online learning changed their perspectives towards learning. Students agreed that their creativity was heightened by creating their blogs in multimodality as they started to publish text and add pictures and photos in order to make the blogs look attractive. They found it motivating that their blogs were more sophisticated compared to their paper-based writing. Such exposure is very invigorating for young age group learners who are in tune with Internet technology. Almost all the learners indicated their plans to carry on pursuing their learning online. The students also expressed that they could write without restrictions, pressures, or anxieties in comparison with their peers. They were capable of writing on the topics fixed by the instructor because of they were able to get assistance from their online learning as well as their friends. Regarding the blog viewers, 19 students preferred both the teacher and the peers to read and provide commentaries on their blog entries. They liked concepts, view exchanges, beneficial criticism, and teacher correction on the writing. Only one student wanted only her classmates to be the audience.

Nevertheless, the students also witnessed some restrictions on online learning, such as Internet connectivity, digital devices, blogging skills, limited language competence. Certain students even pointed out some weaknesses in free online resources, such as being time-consuming, the occurrence of plagiarism, lack of teacher feedback and correction, and bloggers' disclosure of their personal information.

\section{Free Online Implications In Learning English}

Although free online learning indicates some positive feedback compared to other modes of learning, acceptance of it is not as straightforward as a simple yes or no. Educators at all-times need to have proven solutions and information regarding teaching approaches and techniques to promote productivity in the educational sector. The effectiveness of the learning approaches in this sector require attention to various factors such as the targeted students, the fields of study, course design, budgets, and teachers' roles (Liu \& Cavanaugh, n.d.). The outline offered in this report is anticipated to serve as a resource for participants' use in assessing available research. It can also be used as groundwork for future research. As the online learning approach continuously gains popularity, 
educationists will need to look into productivity research such as instructional alternatives' cost effectiveness and how they can build the capacity of all the stakeholders and measure the end results of the teachers, students, and the system itself (Velavan \& Meyer, 2020). The studies designed to cater to education decisions should be based on stringent rules and methodologies to measure the full cost, describe key enactment characteristics, and use reliable assessments of student learning. Regrettably, no studies were found in this study that rigorously analysed the productivity of online learning for secondary and elementary students, even though the presented data proposes that online learning has the potency to progress educational productivity if properly deployed (McAleer, 2020).

Some of the challenges that could be faced by both teachers and the learners are those such as familiarisation with the use of online tools, the capacity to use the medium to draw maximum advantages, teachers being available at times of need, and the ability to provide feedback and quick responses to learners. As for the institutions, they might find some challenges in the cost of implementing online learning facilities. Institutions will need to anticipate the per student costs and the total costs for online learning versus other more traditional methods of learning. Comparatively high total costs may be more palatable if courses can be leveraged across a wider student audience. Optionally, an institution could also transfer some cost to students and their parents by encouraging them to own any necessary multimedia devices such as computers, laptops, printers, or scanners for the purpose of online education. However, there are also some limitations in internet access for some of areas which could cause another set of problems.

As the overall findings show, although the online learning was more effective than traditional learning, and, in fact, blended learning proved to be more productive, much more exploration is required to know how, when, and under what circumstances online learning can produce the greatest productivity gains for all students.

\section{Conclusion}

The findings from this analysis proved that students agreed that the Internet is a useful tool for the medium of instruction. It can be a supplement to in-class instruction, which will enhance better learning. The students considered it as a suitable way to learn English through teacher-recommended ESL websites. However, the students need some guidance from teachers concerning appropriate sites and how to apply them. This finding reflects Paulsen's (2001) remark stating that it is very important to guide students in the use of Internet resources so that they are not misled.

It was evident that the adoption and integration of online resources with traditional methods will lead our education system to success. To make this happen, there are various actions needed to be taken in the areas of education policy, curriculum planning, professional development, infrastructure, community engagement, and access. Realistically, implementation of this approach is not as easy as just setting up computers and getting them connected to the internet. The concern is how the entire education system can adopt this technology as a tool for effective learning by blending aspects of teaching and learning. This view was supported by the finding of Kozma (2005) that placing technology in a school is not an easy option for improving student's learning capacity. The real challenge is in creating consistent relationships between student learning and Information Communication Technology (ICT). Students must treat technology as an intellectual partner and concentrate their learning with technology.

As for the educator's role, the approaches used by them to guide students in making webpages which link to other relevant or recommended sites, coaching students in online navigation, and familiarising them with content found on selected sites were useful and indeed obligatory. Nevertheless, the fulfilment gained from the use of these strategies deployed by the teachers and the contents found in the websites overshadowed the dissatisfaction caused by the difficulty in accessing the assigned websites (Krishnan et al, 2020). Students find it very much disheartening when they spent too much time getting connected to and disconnected from the internet. They observed this problem as an impediment preventing them from completing their assignments on time. 
The data also showed that certain students were not very keen on using online materials such as the ESL websites for their supplementary knowledge except when they were forced to do it. These findings were derived from the follow up done on similar students some months later. The results revealed that students no longer accessed any ESL websites on their own accord for the reason that they did not have access to the online content all the time, as well as having insufficient time for the ESL learning. They found that it was much easier to gain access to traditional methods.

\section{Suggestions and Recommendations}

Based on the above findings, some proposals have been forwarded for further research. Moving forward with rapid changes in information technology, it is very important that younger generations are not left out especially generation Z. By promoting the use of online learning facilities in their language learning, they are indirectly forced to keep aligned with the changes in the world of information technology (IT). However, it is not possible to attain this goal by placing the whole responsibility on the students alone, in fact, many other parties are also required to play their crucial roles in making this successful. An International body called International Society for Technology and Education (ISTE) was established for this matter. They represent educators, and have developed standards of operation for learners, educators, and administrators. Based on their findings, it is recommended that the teachers should develop the skills to inspire and facilitate students for creative learning. They must use their expertise, their learning, and technology for the advancement of students. The teachers should also plan, develop, and assess reliable learning experiences and assessments, integrating modern-day tools and resources to take full advantage of content learning to develop skills, knowledge, and attitudes pertaining to the standards of the students.

Furthermore, encouraging ESL learners to design their own websites is also worthwhile in exploring the possibility of incorporating other authentic web-based materials such as commercial websites and online reference books as part of an ESL curriculum. Researchers should also conduct studies to determine whether online learning achieves the targeted language proficiency through blended learning, especially for ESL/EFL learners, and it is important to integrate various websites to improve their English language proficiency from more internet resources.

\section{Acknowledgement}

My special thanks to Dr. Sridevi Sriniwass, Senior Lecturer, Department of English Language (Faculty of Languages \& Linguistics, University of Malaya) for planting this seed in my head and creating my passion for this study.

\section{References}

Alexander, B. (2006). Web 2.0: A new wave of innovation for teaching and learning? Education Australia, 14.

Atmojo, A. \& Nugroho, A. (2020). EFL Classes Must Go Online! Teaching Activities and Challenges during COVID-19 Pandemic in Indonesia, Register Journal, 13(1). 49-76.

Barab, S. A., Squire, K., \& Dueber, B. (2000). Supporting authenticity through participatory learning. Educational Technology Research and Development, 48(2), 37-62.

Benson, J., \& Reyman, J. (2009). Learning to write publicly: Promises and pitfalls of using weblogs in the composition classroom. Retrieved from http://www.john-benson.net/blogstudy/

Bernard, R. (2000). Social research methods: Qualitative and quantitative approaches. Thousand Oaks, CA: Sage publications.

Campbell, A. P. (2003). Weblogs for use with ESL classes. The Internet TESL Journal, ix (2),112-121. http://iteslj.org/Techniques/Campbell-Weblogs.html

Creswell, J. (2014). Research design: Qualitative, quantitative, and mixed methods approaches (4th ed.). SAGE Publications, Inc. 
Du, H., \& Wagner, C. (2007). Learning with weblogs: Enhancing cognitive and social knowledge construction. IEEE Transactions on Professional Communication, 50(1), 1-16.

Depoe, M. (2001). Guide to online resources. CALL-EJ Online, 2(2). http://www.lerc.ritsumei.ac.jp/callej/5-2/depoe.htm

Drever, E. (1990). Using Questionnaires in Small-Scale Research. Scotland: SCRE Publication

Felix, U. (1999). Exploiting the Web for language teaching: selected approaches. Recall, 11(1), 30-37.

Felix, U. (2001). A multivariate analysis of students' experience of web-based learning. Australian Journal of Educational Technology, 17, (1) 21-36.

Godwin-Jones, B. (2003). Blogs and wikis environments for on-line collaboration. Language Learning \& Technology, 7(2), 12-16. http://llt.msu.edu/vol7num2/emerging/default.html

Howitt, D., \& Cramer, D. (2005). Introduction to statistics in psychology. Harlow: Pearson Hall.

Jackson, S. L. (2012). Research methods statistics. (4th ed.) Chicago, IL: Wadsworth Cengage Learning.

Kavaliauskieno, G., Anusieno, L., \& Mazeikieno, V. (2006). Application of blogging for learner development. Journal of Language and Learning, 4(2), 133-143.

Kitao, K., \& Kitao, K. (2000). On-line resources and journals: ELT, linguistics, and communication. Retrieved from http://www.ling.lancs.ac.uk/staff/visitors/kenji/onlin.htm

Krafcik, M. 2010. Monongalia alters Summer school program. Retrieved from http://yourwvabc.com/story.cfm?func=viewstoryandstoryid=73739

Kress, G. (2013). Literacy in the New Media Age. London, United Kingdom: Routledge.

Kress, G. (2003). Literacy in the New Media Age.London, United Kingdom: Routledge.

Krishnan, I.A, Mello, G., Kok, S.A, Sabapathy, S., Munian, S., Ching, H.S, Kandasamy, P., Ramalingam, S., Baskaran, S. \& Kanan, V. (2020). Challenges Faced by Hearing Impairment Students During COVID-19, Malaysian Journal of Social Sciences and Humanities (MJSSH), $5(8), 106-116$.

Kozma, R. (2005). National policies that connect ICT-based education reform to economic and social development. Human Technology, 1(2), 117-156.

Li, R. C., \& Hart, R. S. (1996). What can the World Wide Web offer ESL teachers? TESOL Journal, $5-10$.

Lin, C. H., Zhang, Y., \& Zheng, B. (2017). The roles of learning strategies and motivation in online language learning: A structural equation modeling analysis. Computers and Education, 113, $75-$ 85.

LeCompte, M., \& Schensul, J. (1999). Essential ethnographic methods: Ethnographers toolkit. New York, NY: Altamira Press.

Leow, R., Cerezo, L., \& Baralt, M. (2015). A psycholinguistic approach to technology and language learning. Boston, MA: De Gruyter.

Liu, F., \& Cavanaugh, C. (n.d.). Online core course success factors in virtual school: Factors influencing student academic achievement. International Journal of E-Learning.

Marta, L. M.C. (2018). Comparing online English language learning and face-to-face comparing online English language learning and face-to-face English language learning at el Bosque university in Colombia. (Doctoral dissertation). Retrieved from https://scholarscompass.vcu.edu/etd

Meloni, C. (1998). The Internet in the classroom: A valuable tool and resource for ESL/EFL teachers. ESL Magazine. http://www.eslmag.com/Article.htm

Meloni, C. (2000). The Internet in the classroom: A valuable tool and resource for ESL/EFL Teachers. ESL Magazine. Available://www.eslmag.com/Article.htm

McAleer, M. (2020). Prevention Is Better Than the Cure: Risk Management of COVID-19. Journal of Risk and Financial Management, 13(3). https://doi.org/10.3390/jrfm13030046

Murray, L., \& Hourigan, T. (2008). Blogs for specific purposes: Expressivist or sociocognitivist approach? ReCall, 20(1), 82-97.

Mynard, J. (2007). A blog as a tool for reflection of English language learners. Asian EFL Journal, November: 1-10. http://www.asian-efl-journal.com/pta_Nov_07_jm.pdf

Olster, S. (2010, July 27). Summer school goes online. Fortune. http://tech.fortune.cnn.com/2010/07/27/ summer-school-goes-online.

Osuna, M. M., \& Meskill, C. (1998). Using the World Wide Web to integrate Spanish language and culture: A pilot study. Language Learning \& Technology, 1(2), 71-92. 
Oravec, J. (2002). Bookmarking the world: Weblog applications in education. Journal of Adolescent and Adult Literacy, 45(7), 616-621.

Picciano, A., \& Seaman, J. (2009). K-12 online learning: A 2008 follow-up of the survey of U.S. school district administrators. Needham, MA: Sloan Consortium. http://www.sloanconsortium.org/publications/survey/pdf/k-12_online_learning_2008.pdf

Pathak, A., \& Charatdao, I. (2012). Use of semi-structured interviews to investigate teacher perceptions of student collaboration. Malaysian Journal of ELT, 8(1). http://www.researchgate.net/publication/271138816

Paulsen, P. (2001). New era trends and technologies in foreign language learning: An annotated bibliography. Interactive Multimedia Electronic Journal of Computer-Enhanced Learning. http://imej.wfu.edu/articles/2001/1/05/index.asp

Pinkman, K. (2005). Using weblogs in the foreign language classroom: Encouraging learner $\begin{array}{lllll}\text { independence. The JALT CALL Journal, } & \text { 1(1), }\end{array}$ http://www.jaltcall.org/journal/articles/1_1_Pinkman.pdf

Rahman, M. M., Singh, M. K. M., \& Pandian, A. (2018). Exploring ESL teacher beliefs and classroom practices of clt: A case study. International Journal of Instruction, 11(1), 295-310.

Riel, M., \& Polin, L. (2004). Online communities: Common ground and critical differences in designing technical environments. In S. A. Barab, R. Kling, \& J. H. Gray (Eds.), Designing for virtual communities in the service of learning (pp. 16-50). Cambridge, MA: Cambridge University Press.

Schwen, T. M., \& Hara, N. (2004). Community of practice: A metaphor for online design. In S. A. Barab, R. Kling, \& J. H. Gray (Eds.), Designing for virtual communities in the service of learning (pp. 154-178). Cambridge: Cambridge University Press.

Sevelj, M. (2006). Weblogs as dynamic learning spaces. Retrieved from http://grail.oise.utoronto.ca/blog/karaisko/files/2007/12/weblogs_dynamic_learning_spaces.pdf

Shahida Naz, Memona Rasheed \& Tahir Rasheed. (2019). The role of smartphones in learning English: A study of learners' perspectives. International Conference on Research in Humanities, London United Kingdom, 1(2)17-28.

Shamim, F. (2017). English as the language of development in Pakistan: Issues, challenges and possible solutions. See discussions, stats, and author profiles for this publication at: https://www.researchgate.net/publication/313722489.

Singhal, M. (1997). The Internet and foreign language education: Benefits and challenges. The Internet TESL Journal, 3(6). http://iteslj.org/Articles/Singhal-Internet.html

Small, M. (2014). Theoretical implementations of various mobile applications used in English language learning. Teaching English with Technology, 14(1), 35-46.

Smith, D. G. \& Baber, E. (2005). Teaching English with Information Technology: How to Use the Internet and IT When Teaching - for the Professional English language Teacher. London, United Kingdom: Modern English Publishing.

Sperling, D. (1997). The Internet guide for English language teachers. Upper Saddle River, NJ: Prentice Hall Regents.

Sussex, R., \& White, P. (1996). Electronic networking. Annual Review of Applied Linguistics, 16, 200225.

Twigg, C. (2003a). Improving learning and reducing costs: New models for online learning. Educause Review, 38(5), 28-38.

Twigg, C. (2003b). Improving quality and reducing cost: Designs for effective learning. Change, $35(4), 22-29$.

U.S. Department of Education, Office of Educational Technology. (2010a). Transforming American education: Learning powered by technology. National Educational Technology Plan 2010. Washington, DC: Author. http://www.ed.gov/ technology/netp- 2010

Velavan, T. P., \& Meyer, C. G. (2020). The COVID-19 Epidemic. Tropical Medicine and International Health, 25(3), 278-280. ://doi.org/10.1111/tmi.13383

Watson, J., \& Gemin, B. (2008). Using online learning for at-risk students and credit recovery. International Association for $\mathrm{K}-12$ Online Learning (iNACOL). http://www.inacol.org/research/promisingpractices/NACOL_CreditRecovery_Promising Practices.pdf 
Waldeck, J. (2008). The development of an industry-specific online learning center: Consulting lessons learned. Communication Education, 57(4), 452-463.

Watson, J. (2010). Keeping pace with K-12 online learning: An annual review of policy and practice. Durango, CO: Evergreen Education Group.

Ward, J. M. (2004). Blog assisted language learning (BALL): Push button publishing for the pupils. TEFL Web Journal, 3(1), 1-6.

Warschauer, M. (Ed.). (1995). Virtual Connections: Online activities and projects for networking language learners. University of Hawaii: Second Language Teaching \& Curriculum Center.

Warschauer, M. (2000). The changing global economy and the future of English teaching. TESOL Quarterly, 34(3), 511-535.

Wicks, M. (2010). A national primer on $K-12$ online learning. Version 2. Retrieved fromhttp://www.inacol.org/research/docs/iNCL_NationalPrimerv22010-web.pdf

Yang (2005). Does an open forum promote learning among students? A collaborative learning approach.

Zhang, D. (2009). The Application of blog in English writing. Journal of Cambridge Studies, 4(1), 213-218. http://journal.acs-cam.org.uk/data/archive/2009/200901-article8.pdf

\section{Authors' Biodata}

1. Isai Amutan Krishnan is currently doing his $\mathrm{PhD}$ at the Faculty of Languages and Linguistics, University of Malaya (UM), and his area of interests are in human resource development \& management, ELT, and performing arts. He is also a freelance consultant locally and abroad.

E-mail address: amuthan.isai@gmail.com

HP: +60123845100

Address: Faculty of Languages and Linguistics, University of Malaya, 50603 Kuala Lumpur

2. Hee Sio Ching obtained her Masters in ESL from UM and is currently a trainer who specialises in English at the workplace, offering presentation \& communication skill courses. She is also a part-time lecturer with HELP university where she explores students into the field of communication, writing skills, personal branding \& career Management, ESP as well as language in public relation.

E-mail address: ansiehee@hotmail.com

HP: +60133368175

Address: ELM Business School, HELP University, Jalan Sri Semantan 1, Off Jalan Semantan, Bukit Damansara, 50490 Kuala Lumpur

3. Selvajothi Ramalingam $(\mathrm{PhD})$ joined as a senior lecturer in the Faculty of Languages and Linguistics at the University of Malaya (Department of Malaysian Languages and Applied Linguistics) in 2018. Before he joined the faculty, he was a teacher in secondary school and assistant director in Ministry of Education. He completed his Doctoral program in Sociolinguistics, Masters of Modern Languages Studies, and Bachelor of Arts at University Malaya. He also obtained a Diploma in Education and a Diploma in Translation. His main research interests are Sociolinguistics, Applied Linguistics in general, Tamil Linguistics, and Teaching Tamil Language in particular. Areas of particular interest include Language Shift and Maintenance, Ethnolinguistics, Language and Identity, Language and Culture, Minority languages, Mother tongue education, and Translanguaging.

E-mail address: selvajothi@um.edu.my HP: +60192267579

Address: Faculty of Languages and Linguistics, University of Malaya, 50603 Kuala Lumpur 
DOI: https://doi.org/10.47405/mjssh.v5i9.494

4. Elanttamil Maruthai is a lecturer in the Department of Malaysian Languages and Applied Linguistics, Faculty of Languages \& Linguistics, University of Malaya. His area of expertise is Applied Linguistics (discourse and genre studies, corpus linguistics).

E-mail address: elanttamil@um.edu.my

HP: +60123143910

Address: No. 10, Jalan 4/54, 46059 Petaling Jaya, Selangor.

5. Pushpa Kandasamy is currently a secondary school English teacher in the State of Johor, Malaysia. She has been attached to the field of education (Ministry of Education, Malaysia) for 22 years and was awarded for her excellent service and contributions in this field thrice. She has also been appointed as the Excellent Teacher in the year 2017 by the Board of Federal Inspectors of Excellent Teacher Award. She has showcased her innovation during MELTA Conference besides presenting her innovations and was blessed with a few championship awards in the district and state level. She obtained her Masters Degree in The University of Malaya in 2015 and currently working as a teacher besides holding the post of Master Trainer for the district and state level programmes.

E-mail address: puvee2410@yahoo.com

HP: +019919610

Address: SMK Dato’ Bentara Dalam, KM 3 Jalan Genuang, 85000 Segamat Johor.

6. Geraldine De Mello, $\mathrm{PhD}$, is an Associate Professor at the Academy of Language Studies, Universiti Teknologi MARA Melaka. She has taught a number of English courses at the diploma and degree levels. She is actively involved in writing and has written several books. Some of her research articles have also been published in local and international indexed journals. She is also keen in innovating and producing educational tools to help educators teach in a fun way and creating a positive atmosphere among the students in the classrooms.

E-mail address: geraldine@uitm.edu.my

HP: +60123736259

Address: Jabatan Bahasa Inggeris, Akademi Pengajian Bahasa, UiTM Cawangan Melaka.Kampus Alor Gajah. Melaka.

7. Saravanan Munian, obtained his degree in Indian Studies from University of Malaya in 2008. He also obtained Diploma in Education from Teachers' Training Institute. He is currently a teacher in SRJKT Ganesar Serdang, Kedah. He is also interested in research in innovative, teaching and learning. Apart from teaching, he involves in corporate social responsibility.

E-mail address: dr.saravananshiva@gmail.com

HP: +60195529186

8. Wong Woei Ling (Faith) is a School Improvement Specialist Coach attached to the District Education Office. She brags over 20 years of experience in the education field and has presented papers locally and internationally. Her domain of interests are human communication disorders, discourse analysis and technology in the realm of education.

E-mail address: wong.woeiling@moe.gov.my

HP: +60138184929

Address: Kuching District Education Office, Jalan Diplomatik, 93050 Petra Jaya, Kuching, Sarawak. 